\title{
Plasma Deposited Electrocatalytic Films with Controlled Content of Pt Nanoclusters
}

\author{
Elena Dilonardo," Antonella Milella, Pinalysa Cosma, Riccardo d'Agostino, \\ Fabio Palumbo
}

Combining platinum sputtering with plasma polymerization in argon-ethylene plasmas, nanocomposite Pt-hydrocarbon thin films, useful as catalytic layers for proton exchange membrane fuel cells, can be deposited. Pulsing the ethylene flow rate allowed for a fine tuning of the Pt amount in deposited films at low RF input power. The proposed deposition process seems to be an efficient strategy to control the metal content over a wide range of atomic percentages (5-80\%). Deposited films were characterized in terms of their chemical, electrochemical and structural properties. The XPS spectra revealed that platinum is included in the films in metallic state. SEM and TEM analyses showed that nanosized Pt clusters (3-7 nm diameter) are uniformly distributed in a porous columnar film structure. The best electrochemical activity $\left(202 \mathrm{~cm}^{2} \cdot \mathrm{mg}_{\mathrm{Pt}}^{-1}\right)$ was achieved with a $500 \mathrm{~nm}$ thick thin film containing

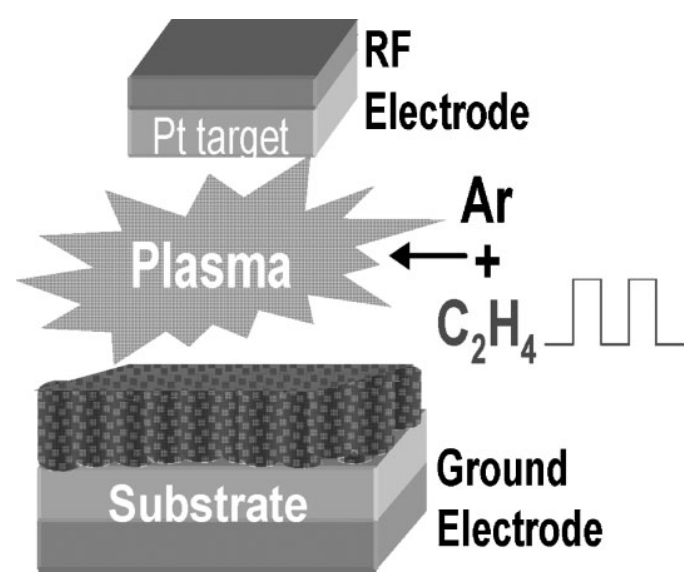
$0.56 \mathrm{mg}_{\mathrm{Pt}} \cdot \mathrm{cm}^{-2}$ of catalyst.

\section{Introduction}

For several years, there has been a growing interest in polymeric materials with embedded metallic nanosized particles as promising candidates for advanced electronic, optical devices and protective coatings against corrosion. ${ }^{[1-3]}$ Of particular interest is the application of these nanocomposites in catalysis, especially highly dispersed nanoscale platinum particles, because of their unique physical and chemical properties. The uniqueness of nanoparticles is mainly due to their large surface area and specific functions

E. Dilonardo, A. Milella, P. Cosma, R. d'Agostino

Department of Chemistry, Università degli studi di Bari "Aldo Moro", Via E. Orabona 4, 70126 Bari, Italy

Fax: +39 0805442024; E-mail: elena.dilonardo@chimica.uniba.it F. Palumbo

Institute for Inorganic Methodologies and Plasmas (IMIP)-CNR,

Via E. Orabona 4, 70126 Bari, Italy which are different from those of either bulk metal. In conjunction with a solid porous support, Pt nanoparticles are applicable in fuel cell technology. ${ }^{[4-6]}$ What is most desirable for this application is the control over particle size, as well as, the oxidation state which affects nanoparticle performances (e.g. catalytic activity). ${ }^{[7]}$ While the preparation of the catalytically active Pt nanoparticles on solid supports is well established utilizing wet chemical process $^{[5,8-11]}$ or physical deposition techniques, ${ }^{[4,12-15]}$ precise control over the particle size, shape and content in the support still remains a challenge. Beside this issue the development of new and environment friendly catalyst preparation methods remains a research task aimed at simplifying the industrial process, reducing fabrication costs and preparation times, while increasing the catalytic efficiency.

Plasma technologies have been involved in catalysis with some success. ${ }^{[16]}$ Most of the studies are related to ultra-fine particles production, direct catalyst deposition on 
a support ${ }^{[17]}$ and also assistance of catalytic reaction. Although very few studies are devoted to low pressure plasma deposition of catalytic thin films, the latter is expected to be advantageous to reduce the catalyst content and to control the nanoparticles distribution in thin films (thickness lower than $2 \mu \mathrm{m}$ ). ${ }^{[18]}$ Another positive aspect of plasma processing is the conformal deposition on microtextured devices, such as micro-fuel cells.

In recent papers, ${ }^{[19,20]}$ we proposed a one-step plasma process, consisting of simultaneous plasma polymerization of ethylene and sputtering from a platinum target, to deposit thin Pt-containing hydrocarbon films to be used as PEM fuel cell electrocatalysts. These previous works showed that the platinum content could be easily controlled by changing the radiofrequency (RF) power and an homogeneous distribution of metal nanoparticles in porous columnar films with good catalytic properties were obtained. The main process drawback was that the Pt content was mainly controlled by the competitive deposition at the target limiting hence its sputtering rate, and as a consequence, high RF power values were needed to get an electrochemically active coating (higher than $500 \mathrm{~W}$ ), while the monomer flow rate was kept low.

The purpose of the present work was then to get a platinum amount high enough to have an high catalytic activity but at mild plasma deposition conditions (i.e. low input power). To achieve this control we tried to act on the competition between the plasma polymerization process and sputtering one through the $100 \%$ modulation of the monomer flow rate, as previously presented by Despax et al. ${ }^{[21,22]}$ The process originality relies on pulsing the monomer mass flow rate that permits an accurate and reproducible control of the metal content over a wide range of concentrations at low power. The key feature of this method is that while the discharge is on, periods over which the monomer is flowing ( $\mathrm{ON}$ time, $T_{\mathrm{ON}}$ ) are alternated to periods where the monomer is not flowing (OFF time, $T_{\mathrm{OFF}}$ ). In this way the plasma polymerization can be reduced enhancing the contribution of metal sputtering enriching the matrix in Pt clusters.

In the present research we investigated the influence of monomer flow rate modulation on the film chemistry, morphology and catalytic activity toward the hydrogen oxidation in acid aqueous solution.

\section{Experimental Part}

\section{Films Preparation and Characterization}

Pt-containing hydrocarbon films were deposited by simultaneous plasma enhanced chemical vapour deposition (PECVD) of ethylene and sputtering of a Pt target using the RF capacitively coupled asymmetric parallel plate reactor described in ref. ${ }^{[19]}$ An input power of $250 \mathrm{~W}$ was applied to the platinum target through the impedance-matching network, while the opposite grounded electrode held the samples. The gas feed was introduced by means of electronic mass flow meters (MKS instruments) through a shower ring positioned close to the upper electrode. Deposition processes were performed at $9 \mathrm{~Pa}$ with mixture of $\mathrm{Ar}(145 \mathrm{sccm})$ and $\mathrm{C}_{2} \mathrm{H}_{4}(1.6 \mathrm{sccm})$. The amount of the latter was regulated by pulsing the mass flow rate, changing the $\mathrm{ON}$ time $\left(T_{\mathrm{ON}}\right)$ in the range $1-5 \mathrm{~s}$, with a period $\left(T=T_{\mathrm{ON}}+T_{\mathrm{OFF}}\right)$ of $5 \mathrm{~s}$. The $T_{\mathrm{ON}}$ parameter, which is the duration of the monomer injection, favours the polymerization whereas during the OFF time $\left(T_{\mathrm{OFF}}\right)$ the target sputtering prevails, as depicted in Figure 1. ${ }^{[21,22]}$

To improve process repeatability, before each experiment the target was cleaned by Ar-sputtering at $600 \mathrm{~W}$ and $7 \mathrm{~Pa}$ for $10 \mathrm{~min}$.

The chemical characterization of deposited films was performed by X-ray photonelectron spectroscopy (XPS), using a Theta Probe spectrometer (Thermo VG Scientific) with a monochromatic Al K $\alpha$ radiation (1486.6 eV) operating at $100 \mathrm{~W}$, at a spot size of $400 \mu \mathrm{m}$ and at a take-off angle of $53^{\circ}$ with respect to the surface normal.

Cleaning of the samples was accomplished prior to the analysis by $10 \mathrm{~s}$ sputtering with $1 \mathrm{kV} \mathrm{Ar}{ }^{+}$and a beam current of $500 \mathrm{nA}$. Survey (0-1 $200 \mathrm{eV}$ ) and high resolution (C1s, O1s and Pt4f) spectra were recorded with a pass energy of 200 and $50 \mathrm{eV}$, respectively. In order to investigate process reproducibility, selected experiments were repeated four times and the differences in atomic percentages among the different samples were 3\% maximum. Angle resolved (AR) XPS analyses in the range $28-78^{\circ}$ were also carried out in order to investigate the in-depth distribution of Pt nanoparticles. In this range of angles the maximum thickness collected was estimated to be around 6-7 $\mathrm{nm}$.

Bulk chemical composition of deposited films was performed by Fourier rransform-infrared spectroscopy (FT-IR). FT-IR analyses were carried out with an Equinox 55 spectrometer (Bruker). Spectra were recorded from 400 to $4000 \mathrm{~cm}^{-1}$ at a resolution of $4 \mathrm{~cm}^{-1}$. In order to minimize interference from contaminants (i.e. water vapour and carbon dioxide), the spectrometer was purged with nitrogen for $15 \mathrm{~min}$ between each measurement. Baseline correction was applied to the spectra, which were then normalized to the film thickness.

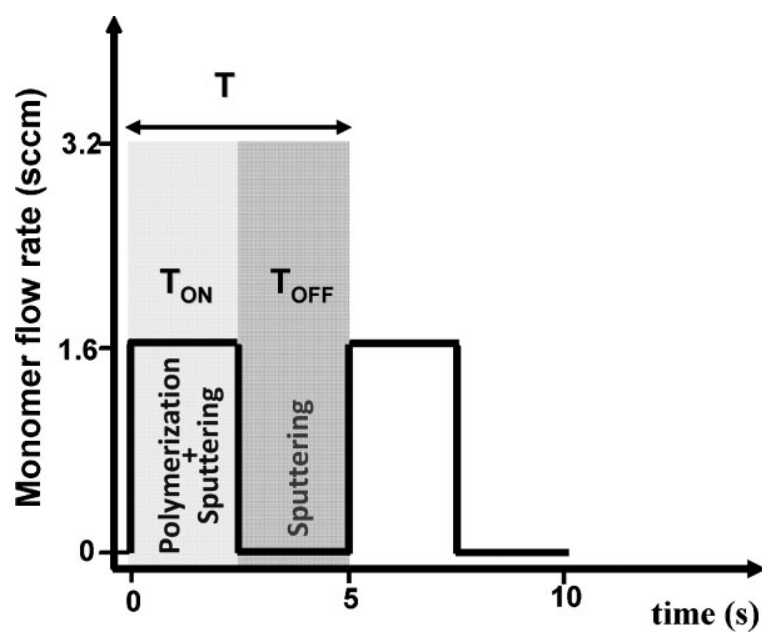

Figure 1. Schematic representation of pulsed monomer flow rate (period: $T=5 \mathrm{~s}=T_{\mathrm{ON}}+T_{\mathrm{OFF}}$ ). 
Film morphology was studied by scanning electron microscopy (SEM), atomic force microscopy (AFM), and transmission electron microscopy (TEM). SEM observation was performed with a Carl Zeiss FESEM-SIGMA scanning electron microscope (at $3 \mathrm{kV}$ ) on samples metalized with gold by sputter coating. AFM images were acquired with an Autoprobe CP Research (ThermoMicroscopeVEECO) in non-contact mode using conical gold coated silicon tips with a resonance frequency around $80 \mathrm{kHz}$. TEM analyses were performed on 20-40 nm thick films deposited directly onto carbon coated copper grids. A Joel-JEM-2010 electron microscope was utilized, operating at $200 \mathrm{kV}$, with a point-to-point resolution close to $0.2 \mathrm{~nm}$. Images were acquired with a Gatan 794 slow scan CCD and processed with the DiffTool package. ${ }^{[23]}$ Bright field images and selected area diffraction (SAD) patterns were obtained in order to check platinum nanoparticle clusters dispersed in the hydrocarbon matrix, and to measure their size and crystalline structure. High resolution (HR) images were also obtained to visualize the crystalline structure of the clusters at nanometer scale.

Film thickness was measured by an $\alpha$-step 500 (TENCOR) profilometer.

The Pt loading in the coating was measured using inductively coupled plasma atomic emission spectroscopy (ICP-AES) analysis, according to the procedure described in ref., ${ }^{[20,24]}$ dissolving the Pt-nanocomposite film in $5 \mathrm{~mL}$ of aqua regia $\left(\mathrm{HCl} 37 \%, \mathrm{HNO}_{3} 70 \%\right.$, in a $3: 1 \mathrm{v} / \mathrm{v}$ ratio).

\section{Electrochemical Analyses}

All cyclic voltammetry (CV) experiments were carried out using a computer controlled PGSTAT10 potentiostat (Autolab Eco-Chemie) at a temperature of $293 \pm 2 \mathrm{~K}$. Chemicals of analytic grade were used. In particular all solutions were prepared in bi-distilled water and were deaerated with the use of high purity argon. The background electrolyte was a $0.5 \mathrm{M} \mathrm{H}_{2} \mathrm{SO}_{4}$ solution. A classical 3-electrode glass cell was used. A saturated $\mathrm{Ag} / \mathrm{AgCl}$ electrode was used as reference electrode, while the counter electrode was a platinum wire. The working electrode was a circular sample (geometric area of $0.07065 \mathrm{~cm}^{2}$ ) maintained in a PTFE holder, which contained a stainless steel screw as electrical contact. The sample was held in place by a bayonet connector, coupling of the stainless steel contact into the working electrode holder, assuring experimental reproducibility when performing multiple experiment. The specific electrochemically active surface area (SECSA) of Ptembedded hydrocarbon films was determined by CV experiments from the charge in the hydrogen desorption potential region $\left(Q_{\text {Hdes }}\right)$, according to the procedure described in ref. ${ }^{[25,26]}$

The calculated charge associated with the desorption of the hydrogen is an indication of the number of surface catalyst atoms present. The electrical charge, $Q$, is defined as the integral of cell current, $I$, with respect to time, $t$. With respect to surface area, the specific electrochemical and geometric values can differ by orders of magnitude. Since the desorption process and the catalytic reaction rates are based on the SECSA, it is important to be able to measure this value. The most widely used electrochemical method to determine the SECSA is as follows. The desorption charge, associated with desorbed hydrogen on a known platinum black electrode surface used as reference, $\underline{Q}_{\text {Hdes }}=210 \mu \mathrm{C} \cdot \mathrm{cm}^{-2}$, and the measured charge associated with the hydrogen desorption from the surface of deposited films, $\underline{Q}$, can be related to the total electrochemical surface area $S\left(\mathrm{~cm}^{2}\right)$, by

$$
S=\frac{\underline{Q}}{Q_{\text {Hdes }}}
$$

Then a roughness factor, $R_{\mathrm{f}}$, is defined in the equation below:

$$
R_{\mathrm{f}}=\frac{S}{S_{\text {geometric }}}
$$

where $S_{\text {geometric }}$ is the geometric area of the electrode.

Normalizing the roughness factor to the catalyst loading the SECSA is obtained:

$$
\mathrm{SECSA}=\frac{R_{\mathrm{f}}}{W}
$$

where $W$ is the catalyst loading $\left(\mathrm{mg}_{\mathrm{Pt}} \cdot \mathrm{cm}^{-2}\right)$.

The behaviour of the electrodes was investigated by sweeping the potential from $-0.2 \mathrm{~V}$ to $1.2 \mathrm{~V}$ versus $\mathrm{Ag} / \mathrm{AgCl}$ sat. at a linear scan rate of $500 \mathrm{mV} \cdot \mathrm{s}^{-1}$ for 200 cycles, followed by a 10 cycle CV between the same potential limits at a scan rate of $10 \mathrm{mV} \cdot \mathrm{s}^{-1}$.

\section{Results and Discussion}

The surface chemical composition of films deposited by pulsing $\mathrm{C}_{2} \mathrm{H}_{4}$ flow rate with a period of $5 \mathrm{~s}$ and variable $\mathrm{ON}$ time was investigated by XPS and results are shown in Figure 2. The Pt content is high and constant below $T_{\mathrm{ON}}$ of $3 \mathrm{~s}$; above this value it decreases almost linearly. In the same ON time interval carbon atomic concentration has an opposite trend, increasing almost linearly for ON time longer than $3 \mathrm{~s}$. These results can be rationalized considering that, at constant pulse period, an increase of $T_{\mathrm{ON}}$ (duration of the monomer injection) results in an higher average monomer flow rate. Since more hydrocarbon precursor is then available in the plasma, the contribution

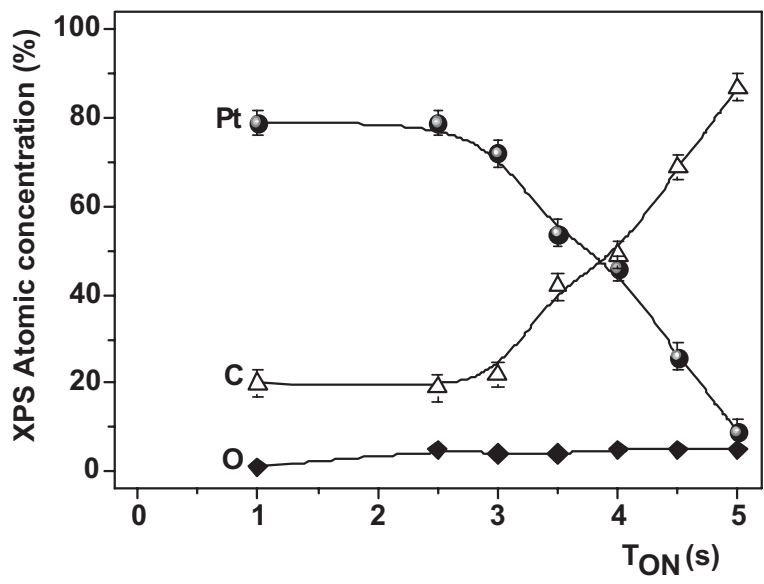

Figure 2. XPS atomic percentages versus $T_{\mathrm{ON}}$ with a period of $5 \mathrm{~s}$. 
of polymerization both on the target and in the coating is more pronounced. Correspondingly the Pt content in the deposited films should decrease.

Some considerations can be further elaborated comparing the pulsing parameters with the monomer residence time, $\tau$, (i.e. the mean time the gas molecules remain in the process chamber before being pumped away). Based on the volume of the reactor chamber ${ }^{[19]}$ and the monomer flow rate of $1.6 \mathrm{sccm}$, the residence time is $2.5 \mathrm{~s}$. The described process consists of periods where the monomer flow is on, along with that of Argon, alternating with those during which only Ar is flowing. However, when the monomer is switched off a time equal to $\tau$ is roughly necessary to pump out $\mathrm{C}_{2} \mathrm{H}_{4}$. Since the period of modulation is fixed to $5 \mathrm{~s}$, for ON time as long as $2.5 \mathrm{~s}$ the residual $T_{\text {OFF }}$ is enough for complete evacuation of the monomer, allowing the effective sputtering of the target, carried out mostly by argon ions, while the plasma polymerization is reduced. On the other hand when the ON time is higher than $2.5 \mathrm{~s}, T_{\text {OFF }}$ is shorter than $\tau$ and during the single pulse the monomer cannot be exhausted efficiently, and it can even accumulate. In these conditions the contribution of hydrocarbon polymerization becomes important even during the OFF time, and the $\mathrm{Pt} / \mathrm{C}$ ratio should decrease. ${ }^{[27]}$

It can be also observed, that, when processing the samples in pulsed mode, the atomic metal content can be changed in the range $25-80 \%$, while in continuous mode (Figure 1, at $T_{\mathrm{ON}}=T=5 \mathrm{~s}$ ) at the same power the platinum content is lower than $10 \%$.

Figure 2 also shows that a residual amount of oxygen (lower than 7\%) is always present in the film. Since XPS depth profiles indicate that oxygen is present only at the surface of the film, in the topmost $10-20 \mathrm{~nm}$, it can be argued that the oxygen content is due to uptake upon exposure to the atmosphere. Even if the presence of oxygen is limited to the topmost layers, and its concentration is low, a deeper evaluation of its bonding environment was carried out. To have indication about the oxygen bonding the bestfitting of $C$ 1s signal was performed. ${ }^{[28,29]}$ The latter was accomplished with two components at $285 \mathrm{eV}(\mathrm{C}-\mathrm{C}, \mathrm{C}-\mathrm{H})$ and $287 \mathrm{eV}(\mathrm{C}=\mathrm{O}, \mathrm{C}-\mathrm{O})$. The peak area in atomic percent relative to the oxygenated carbon at higher binding energy was always close to the oxygen amount in the film, thus allowing to rule out any Pt oxidation. This is an important issue for catalytic applications, where the active species is mainly non-oxidized platinum. ${ }^{[30]}$ A detailed XPS study was also carried out on the Pt4f peak, which consists of a doublet due to spin-orbit splitting: $\mathrm{Pt}_{4} \mathrm{f}_{5 / 2}$ at $74.5 \mathrm{eV}$ and $\mathrm{Pt} 4 \mathrm{f}_{7 / 2}$ at $71.2 \mathrm{eV} \cdot{ }^{[4,31,32]}$ Binding energy (BE) and full width half maximum (FWHM) of $\mathrm{Pt}_{4 f_{7 / 2}}$ are reported in Table 1 . It can be observed that the BE and the FWHM values for composite films are systematically higher than those of bulk platinum and increase as Pt content decreases. The shift and broadening of XPS Pt signal can be caused by different
Table 1. XPS Pt $4 \mathrm{f}_{7 / 2}$ peak parameters for nanocomposite films deposited at different $T_{\mathrm{ON}}$.

\begin{tabular}{|c|c|c|c|}
\hline$T_{\mathrm{ON}}$ & XPS Pt & $\mathrm{Pt}_{4 / 2} \mathrm{BE}$ & $\mathrm{Pt4f}_{7 / 2}$ FWHM \\
\hline $\mathbf{s}$ & $\%$ & eV & Units \\
\hline 5 & 9 & 72.1 & 1.98 \\
\hline 4 & 46 & 72.0 & 1.88 \\
\hline 3.5 & 54 & 71.9 & 1.71 \\
\hline 3 & 72 & 71.7 & 1.66 \\
\hline 2.5 & 79 & 71.5 & 1.65 \\
\hline 0 & 100 & 71.2 & 1.64 \\
\hline
\end{tabular}

factors: (i) presence of oxidized metal, (ii) differential charging on insulating samples, (iii) nanoparticle size effect. $^{[33-35]}$ Since oxygen was demonstrated to be bonded to carbon and no differences were detected by recording XPS signals with and without the flood electron gun to compensate an eventual differential charging, variations in the $\mathrm{Pt}_{4 \mathrm{f}}$ /2 peak position and broadening can be ascribed only to particle size effects. It is well known, ${ }^{[32-34]}$ in fact, that the BE and FWHM of signals generated by nanodispersed metal clusters systematically increase as the average cluster sizes decreases. This size effect has been attributed to the reduced ability of small particles to screen the final state potential arising in the core-hole after the photoionization process by means of the conduction electrons. ${ }^{[34]}$

Film ageing upon storage in air was studied by XPS. Analyses performed after one month from the deposition did not show any appreciable variation in terms of atomic concentration with respect to the analyses performed on the as-deposited films, in that atomic concentrations vary within the experimental error.

The deposition rate of films obtained by pulsing the monomer flow rate was determined and resulted to be $16 \pm 1 \mathrm{~nm} \cdot \mathrm{min}^{-1}$, independently from the ON time. This value is higher than that of film deposited at the same plasma conditions but with a continuous monomer flow $\left(9 \mathrm{~nm} \cdot \mathrm{min}^{-1}\right)$.

Based on the above-mentioned results, pulsing the monomer flow rate apparently prevents the target contamination and, as a consequence, the sputtering is always efficient, maintaining the overall deposition rate constant. $^{[19]}$

Considering that the process is carried out in pulsing mode, it is reasonable to suppose that the coating could consists of alternating layers with different Pt content. Since the investigation of the chemical composition through the film profile gives information about a possible variation of the species concentration along the film thickness, an angle resolved XPS analysis was performed as not destructive analysis method. XPS atomic percentages 


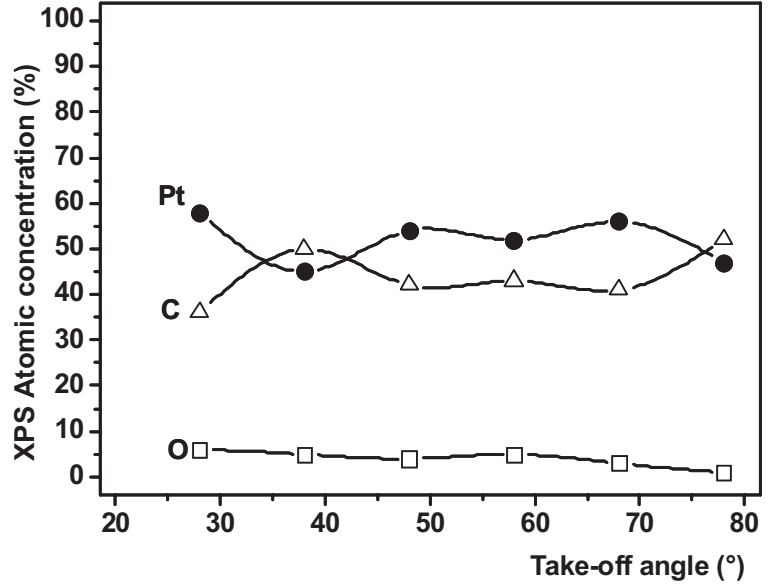

Figure 3. AR-XPS atomic percentages of film deposited at $3.5 \mathrm{~s} T_{\mathrm{ON}}$.

of $500 \mathrm{~nm}$ thick film, deposited at $3.5 \mathrm{~s} T_{\mathrm{ON}}$, were analysed at different take-off angles. Based on the deposition rate, a film thickness of about $1 \mathrm{~nm}$ should be deposited over a pulsing period of $5 \mathrm{~s}$. This validated the use of AR-XPS analysis to investigate the multilayer formation, collecting a maximum thickness of $6-7 \mathrm{~nm}$. Figure 3 reports the atomic percentages as a function of the take-off angles. The angle resolved analysis reveals a certain not homogeneous Pt content throughout the collected film thickness. This result can be justified with the variation of the monomer flow rate over the pulsing period. More specifically the maximum variation in the Pt percentage was found to be $15 \%$.

Bulk chemical composition of the deposited films was investigated by FT-IR. Spectra of films obtained at two different $T_{\mathrm{ON}}, 2.5$ and $4.5 \mathrm{~s}$, are reported in Figure 4 . As for previous plasma deposited nanocomposite films, ${ }^{[19]}$ FT-IR spectroscopy revealed the hydrocarbon nature of the polymeric matrix, despite the difficult assignments of the absorption signals due to a tail of plasmon absorption interference and vibrations of the embedded platinum. Furthermore, some O-containing functional groups are evidenced by the absorption band relative to $\mathrm{O}-\mathrm{H}$ (3 $\left.400 \mathrm{~cm}^{-1}\right), \mathrm{C}=\mathrm{O}\left(1700 \mathrm{~cm}^{-1}\right)$ and $\mathrm{C}-\mathrm{O}$ $\left(1200 \mathrm{~cm}^{-1}\right)$, confirming the presence of carbon atoms bonded to oxygen, as found by XPS analyses. Comparing these two FTIR spectra, it can be observed that at low $T_{\mathrm{ON}}(2.5 \mathrm{~s})$ the absorption of hydrocarbon bands becomes very low, which is reasonable considering that the film mainly consists of platinum atoms.

Film ageing in air was also studied by FTIR. Any appreciable variation was not detected after one month of film storage in air with respect to the as deposited films.

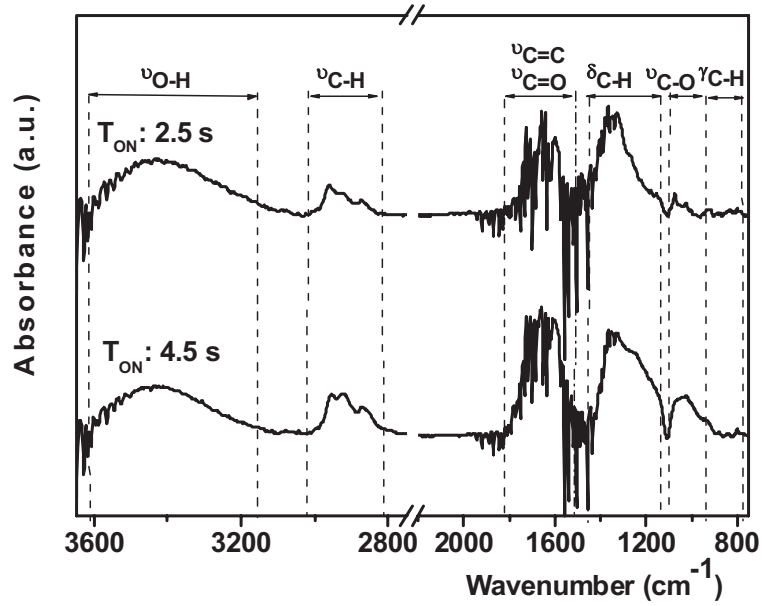

Figure 4. FT-IR spectra of films deposited at 2.5 and $4.5 \mathrm{~S} T_{\mathrm{ON}}$.

SEM images in Figure 5 show the cross-section of nanocomposite films with different Pt amount. The film deposited at a $T_{\mathrm{ON}}$ of 2.5 (Figure $5 \mathrm{~A}$ ), containing a high Pt content, is characterized by a definite, homogeneous columnar microstructure, typical of sputtered films. The morphology of film deposited at high $T_{\mathrm{ON}}$ with a very low $\mathrm{Pt}$ content (Figure 5B), is more compact without a definite microstructure, typical of PECVD processes. The difference in the film morphology can be ascribed to the variation of the film chemical composition that, in turn, depends on the predominance of the sputtering or polymerization process. ${ }^{[19,36]}$ AFM images, reported in Figure 6, confirmed the results obtained by SEM analyses. The increase of surface roughness with the increase of Pt content indicates the evolution of the film morphology towards more porous films characterized by progressively larger nodular structures.

In Figure 7, HR-TEM images of films deposited at 5 and $3.5 \mathrm{~s}$ are reported. TEM analysis and diffraction patterns in the inset revealed that nano-crystalline Pt aggregates in clusters uniformly dispersed in an amorphous hydrocarbon matrix. The dimension of these aggregates of nanoparticles
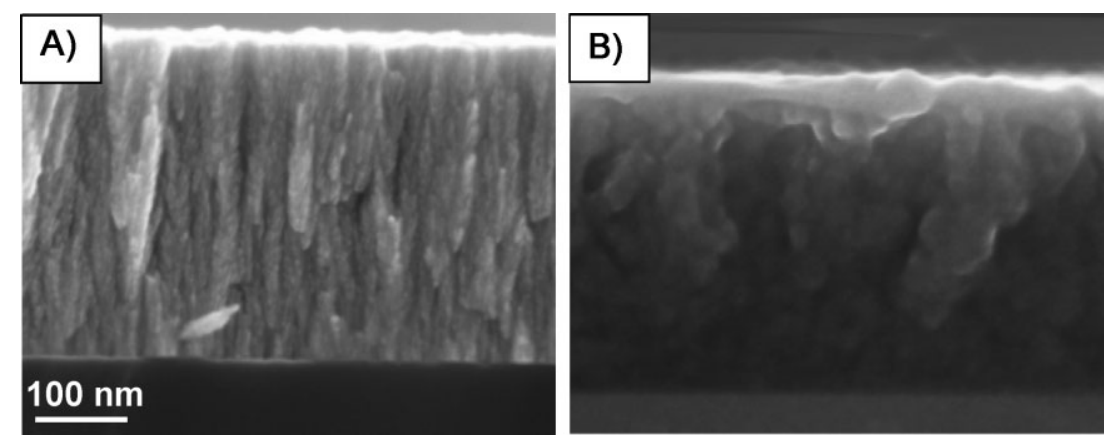

Figure 5. SEM images of Pt-embedded hydrocarbon films deposited at ON time of (A) $2.5 \mathrm{~S} \mathrm{(79 \%} \mathrm{Pt)} \mathrm{and} \mathrm{(B)} 4.5 \mathrm{~s}$ (26\% Pt). 

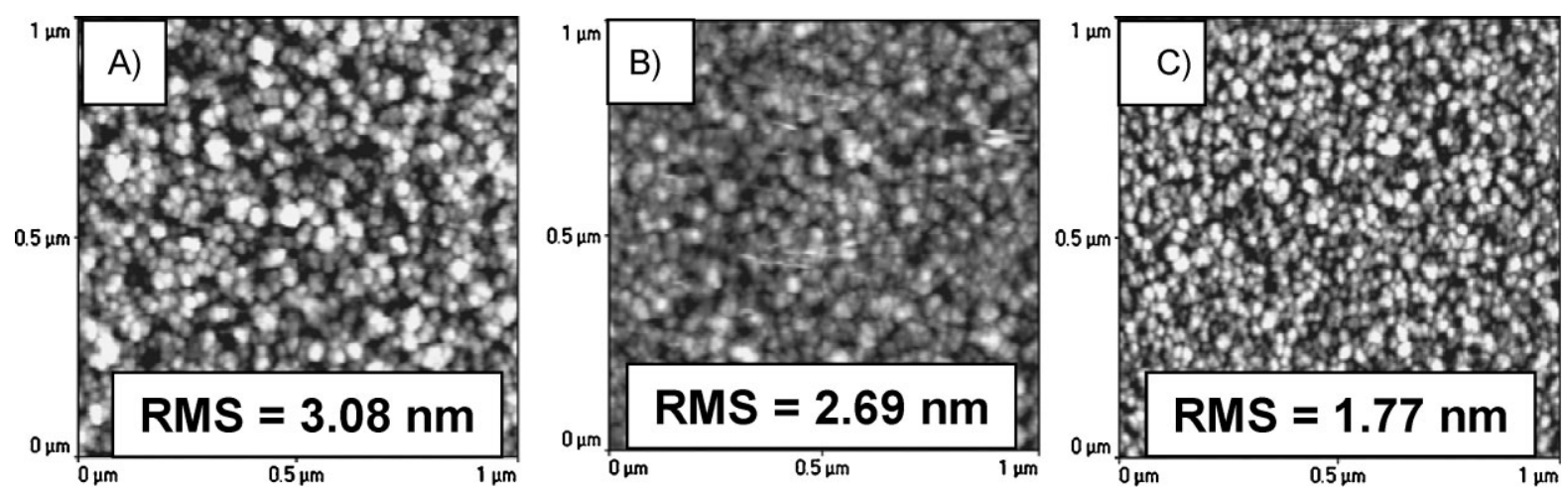

Figure 6. AFM images of Pt containing hydrocarbon films deposited at ON time of (A) $2.5 \mathrm{~s}$ (79\% Pt), (B) $3.5 \mathrm{~s}(54 \% \mathrm{Pt})$, and (C) $4.5 \mathrm{~s}$ (26\% Pt).
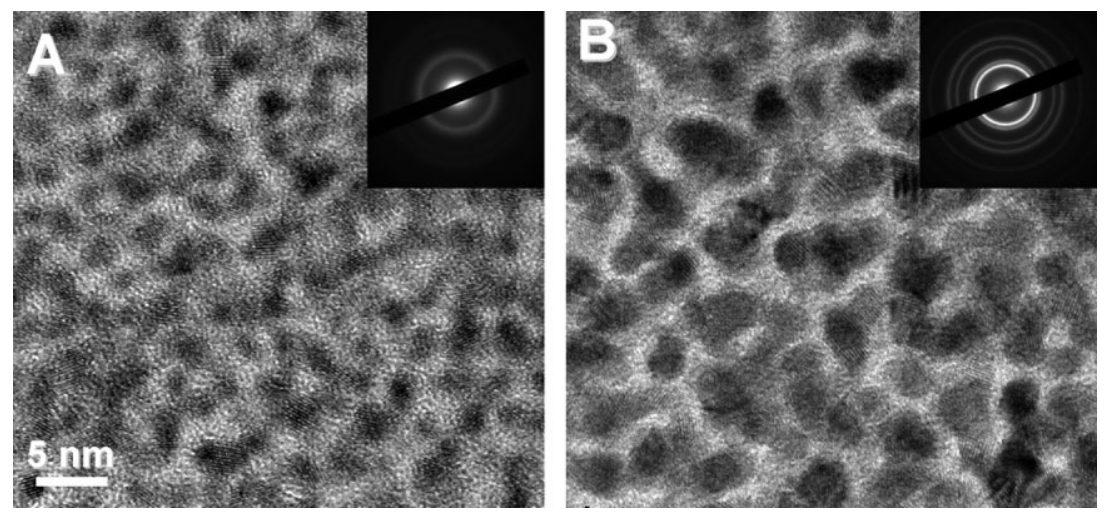

Figure 7. HR-TEM images and SAD (inset) of films deposited at ON time of (A) $5 \mathrm{~s} \mathrm{(9 \%} \mathrm{Pt)}$ and (B) $3.5 \mathrm{~s}(54 \% \mathrm{Pt})$.

increases with the metal content. Comparison of the present results with those reported in a previous work ${ }^{[19]}$ suggests that Pt particles size distribution and crystallinity are only affected by the deposited metal content and not by the process deposition conditions.

Cyclic voltammetry (CV) analyses were carried out to determine the specific catalytic active area of selected samples deposited at different $T_{\mathrm{ON}}$. The active Pt surface was obtained by measuring the charge required for the hydrogen desorption from the Pt surface in sulphuric acid solution. In Table 2 the roughness factor $\left(R_{\mathrm{f}}\right)$ and the specific

Table 2. Electrochemical measurements of Pt-containing hydrocarbon films deposited at different $T_{\mathrm{ON}}$.

\begin{tabular}{|c|c|c|c|c|}
\hline$T_{\mathrm{ON}}$ & XPS Pt & Pt loading & $R_{\mathrm{f}}$ & SECSA \\
\hline $\mathbf{s}$ & $\%$ & $\mathrm{mg}_{\mathrm{Pt}} \cdot \mathrm{cm}^{-2}$ & $\mathrm{~cm}^{2} \cdot \mathrm{Pt} \cdot \mathrm{cm}^{-2}$ & $\mathrm{~cm}^{2} \cdot \mathrm{mg}_{\mathrm{Pt}}^{-1}$ \\
\hline 2.5 & 79 & 0.56 & 113 & 202 \\
\hline 3.5 & 54 & 0.42 & 78 & 186 \\
\hline 4.5 & 26 & 0.20 & 32 & 160 \\
\hline 5 & 9 & 0.07 & 8 & 114 \\
\hline
\end{tabular}

electrochemically active surface area (SECSA) of $500 \mathrm{~nm}$ thick films with different Pt loading, measured by inductively plasma atomic emission spectroscopy (ICP-AES) are reported. The $R_{\mathrm{f}}$ factor increases with the Pt content in the film. The small roughness factor at low Pt loading can be ascribed to the minor amount of catalyst, to a reduced electrical conduction since the hydrocarbon matrix is an insulator, and to the amorphous and compact film structure. The increase of $R_{\mathrm{f}}$ factor with the amount of deposited Pt is probably due to the high catalyst loading which apparently prevails over the negative effect of the cluster size enlargement, as witnessed by TEM and AFM analyses. Furthermore, it should also be considered that the film porosity at high Pt content positively affect the catalytic activity. According to the reported results, the catalytic efficiency of Pt catalyst depends on the catalyst loading and also on film morphology, metal cluster dimension and film porosity.

The plasma deposited thin nanocomposite films have comparable or higher values of $R_{\mathrm{f}}$ and SECSA than those normally obtained with commercial electrocatalyst found in literature and much thinner. ${ }^{[37]}$ In comparison with the process reported in previous work, ${ }^{[19]}$ the one proposed in this paper permits to deposit in milder plasma deposition condition (i.e. lower input power) films with comparable catalytic activity.

\section{Conclusion}

In summary, we have illustrated a plasma deposition method to obtain hydrocarbon thin catalytic films with controlled metal content and film morphology. The methodology for depositing these nanocomposite films is based on a one step plasma process, where the relative 
contribution of plasma polymerization with respect to platinum sputtering is controlled by pulsing the monomer flow rate. The balance between the monomer residence time and the duration of the ON time, with a fixed pulse period, allows to tailor the platinum concentration in the coating. At the same time the morphology, structure and electrochemical behaviour of the layers depend on the Pt content. Thin electrocatalytic layers with activity similar to commercial ones were obtained with a versatile process.

Acknowledgements: The research leading to these results has received funding from the European Union Seventh Framework Program (FP7/2007-2013) under grant agreement NMP3-SL-2009227177 SMALLINONE. Dr. G. Capitani is acknowledged for HR-TEM analysis. Dr. G. Lamedica and Dr. A. Valente are thanked for SEM analyses.

Received: November 24, 2010; Revised: February 2, 2011; Accepted: February 8, 2011; DOI: 10.1002/ppap.201000184

Keywords: electrocatalyst; metal-containing coatings; plasma enhanced chemical vapor deposition; Pt nanoparticles; sputtering

[1] W. U. Huynh, J. J. Dittmer, A. P. Alivisatos, Science 2002, 295, 2425.

[2] R. J. Tseng, J. Huang, J. Ouyang, R. B. Kaner, Y. Yang, Nano. Lett. 2005, 5, 1077.

[3] M. A. Malik, M. T. Galkowski, H. Bala, B. Grzybowska, P. J. Kulesza, Electrochim. Acta 1999, 44, 2157.

[4] T. You, O. Niwa, T. Horiuchi, M. Tomita, Y. Iwasaki, Y. Ueno, S. Hirono, Chem. Mater. 2002, 14, 4796.

[5] J. Prabbhuram, X. Wang, C. L. Hui, I.-M. Hsing, J. Phys. Chem. B 2003, 107, 11057

[6] M. Chen, Y. Xing, Langmuir 2005, 21, 9334.

[7] M. J. Hostetler, J. E. Wingate, C.-J. Zhong, J. E. Harris, R. W. Vachet, M. R. Clark, J. D. London, S. J. Green, J. J. Stokes, G. D. Wignall, G. L. Glish, M. D. Porter, N. D. Evans, R. W. Murray, Langmuir 1998, 14, 17.

[8] R. Narayanan, M. A. El-Sayed, Nano Lett. 2004, 4, 1343.

[9] S. Shanmugam, U. Simon, Chem. Eur. J. 2008, 14, 8776.

[10] V. Kannauaram, V. Veedu, A. M. Kannan, J. Power Sources 2009, 188, 51.
[11] B. E. Morales, S. A. Gamboa, U. Pal, R. Guardian, D. Acosta, C. Magana, X. Mathew, Int. J. Hydrogen Energy 2010, 35, 4215.

[12] A.-L. Thomann, J. R. Rozenbaum, P. Brault, C. Andreazza-Vignolle, P. Andreazza, Appl. Surf. Sci. 2000, 158, 172.

[13] H. Rabat, P. Brault, Fuel Cells 2008, 2, 81.

[14] H. Rabat, C. Andreazza, P. Brault, A. Caillard, F. Béguin, C. Charles, R. Boswell, Carbon 2009, 47, 209.

[15] E. Slvacheva, G. Ganske, G. Topalov, W. Mokwa, U. Schnakenberg, Appl. Surf. Sci. 2009, 255, 6479.

[16] C. J. Liu, J. Zu, K. Yu, D. Cheng, Y. Han, J. Zhan, C. Ratanatawate, B. W.-L. Jang, Pure Appl. Chem. 2006, 78, 1227.

[17] A. Berthet, A. L. Thomann, F. J. Cadete Santos Aires, M. Brun, C. Deranlot, J. C. Bertolini, J. P. Rozenbaum, P. Brault, P. Andreazza, J. Catal. 2000, 190, 49.

[18] S. I. Randolph, J. D. Fowkes, A. V. Melechko, K. L. Klein, H. M. Meyer, M. L. Simpson, P. D. Rack, Nanotechnology 2007, 18, 465304.

[19] E. Dilonardo, A. Milella, F. Palumbo, G. Capitani, R. d'Agostino, F. Fracassi, Plasma Process. Polym. 2010, 7, 51.

[20] E. Dilonardo, A. Milella, F. Palumbo, J. Thery, S. Martin, G. Barucca, P. Mengucci, R. d'Agostino, F. Fracassi, J. Mater. Chem. 2010, 20, 10224.

[21] B. Despax, P. Raynaud, Plasma Process. Polym. 2007, 4, 127.

[22] C. Saulou, B. Despax, P. Raynaud, S. Zanna, P. Marcus, M. Mercier-Bonin, Appl. Surf. Sci. 2009, 256S, S-35.

[23] D. R. G. Mitchell, Microsc. Res. Tech. 2008, 71, 588.

[24] P. Bruno, M. Caselli, M. L. Curri, A. Genga, R. Striccoli, A. Traini, Anal. Chim. Acta 2000, 410, 193.

[25] M. J. Watt-Smith, J. M. Friederich, S. P. Rigby, T. R. Ralph, F. C. Walsh, J. Phys. D: Appl. Phys. 2008, 41, 174004.

[26] J.-H. Wee, K.-Y. Lee, S. H. Kim, J. Power Sources 2007, 165, 667.

[27] M. Bauer, V. Schwarz-Selinger, H. Kang, A. von Keudell, Plasma Sources Sci. Technol. 2005, 14, 543.

[28] M. Gustavsson, H. Fredriksson, B. Kasemo, Z. Jusys, J. Kaieser, C. Jun, J. Electroanal. Chem. 2004, 568, 371.

[29] J. Guo, X. Wang, B. Xu, Mater. Chem. Phys. 2009, 113, 179.

[30] Z. Liu, L. M. Gan, L. Hong, W. Chen, J. Y. Lee, J. Power Sources 2005, 139, 73.

[31] M. Sevilla, C. Sanchis, T. Valdes-Solis, E. Morallon, A. B. Fuertes, J. Phys. Chem. C 2007, 111, 9749.

[32] N. Soin, S. S. Roy, L. Karlsson, J. A. McLaughlin, Diamond Rel. Mater. 2010, 19, 595.

[33] N. Cioffi, I. Losito, L. Torsi, I. Fearella, A. Valentini, L. Sabbatini, P. G. Zambonin, T. Bleve-Zacheo, Chem. Mater. 2002, 14, 804.

[34] L. Orbeli, R. Monot, H. J. Mathieu, D. Landolt, J. Bullet, J. Surf. Sci. 1981, 106, 301.

[35] F. Parmigiani, E. Kay, p. S. Bagus, C. J. Nelin, J. Electron Spectrosc. Relat. Phenom. 1985, 35, 257.

[36] B. Dumay, E. Finot, M. Theobald, O. Legaie, J. Durand, P. Baclet, J. P. Goudonnet, J. Appl. Phys. 2002, 92, 6572.

[37] S. H. Joo, C. Pak, D. J. You, S.-A. Lee, H. I. Lee, J. M. Kim, H. Chang, D. Seung, Electrochim. Acta 2006, 52, 1618. 